\title{
Succinate in Dystrophic White Matter: A Proton Magnetic Resonance Spectroscopy Finding Characteristic for Complex II Deficiency
}

\author{
Knut Brockmann, MD, ${ }^{1}$ Alf Bjornstad, MD, ${ }^{2}$ Peter Dechent, PhD ${ }^{3}$ Christoph G. Korenke, MD, ${ }^{1}$ \\ Jan Smeitink, MD, ${ }^{4}$ J. M. Frans Trijbels, MD, ${ }^{4}$ Sabine Athanassopoulos, MD, ${ }^{5}$ Rafael Villagran, MD, ${ }^{6}$ \\ Ola H. Skjeldal, MD, ${ }^{2}$ Ekkehard Wilichowski, MD, ${ }^{1}$ Jens Frahm, PhD, ${ }^{3}$ and Folker Hanefeld, $\mathrm{MD}^{1}$
}

\begin{abstract}
A deficiency of succinate dehydrogenase is a rare cause of mitochondrial encephalomyopathy. Three patients, 2 sisters and 1 boy from an unrelated family, presented with symptoms and magnetic resonance imaging signs of leukoencephalopathy. Localized proton magnetic resonance spectroscopy indicated a prominent singlet at $2.40 \mathrm{ppm}$ in cerebral and cerebellar white matter not present in gray matter or basal ganglia. The signal was also elevated in cerebrospinal fluid and could be identified as originating from the two equivalent methylene groups of succinate. Subsequently, an isolated deficiency of complex II (succinate:ubiquinone oxidoreductase) was demonstrated in 2 patients in muscle and fibroblasts. One of the sisters died at the age of 18 months. Postmortem examination showed the neuropathological characteristics of Leigh syndrome. Her younger sister, now 12 months old, is also severely affected; the boy, now 6 years old, follows a milder, fluctuating clinical course. Magnetic resonance spectroscopy provides a characteristic pattern in succinate dehydrogenase deficiency.
\end{abstract}

Ann Neurol 2002;52:38-46

Defects of oxidative phosphorylation give rise to heterogeneous clinical symptoms ranging from isolated organ dysfunction to multisystem disorder. ${ }^{1}$ Leigh syndrome and leukoencephalopathies are part of the spectrum of neurological diseases representing a common neuropathological substrate to diverse genetic and biochemical defects. ${ }^{2}$ Abnormalities of complexes I, III, $\mathrm{IV}$, and $\mathrm{V}$ resulting from defects of the mitochondrial and nuclear genome have been identified as major causes in these patients.

A deficiency of complex II represents a rare cause of mitochondrial encephalomyopathy and may be associated with Leigh syndrome and leukodystrophy, ${ }^{3,4}$ lateonset optic atrophy and ataxia, ${ }^{5}$ myopathy with exercise intolerance, ${ }^{6,7}$ and isolated cardiomyopathy. ${ }^{8}$

Complex II (succinate:ubiquinone oxidoreductase, E.C.1.3.5.1.) consists of the soluble active enzyme succinate dehydrogenase $(\mathrm{SDH})$ and two membrane-anchored proteins (SDHC and SDHD). SDH is composed of a flavoprotein and an iron-sulfur protein subunit (SDHA and SDHB). It catalyzes the oxidation of succinate to fumarate in the Krebs cycle and carries electrons to the ubiquinone pool of the respiratory chain.?

In contrast to all other complexes of the mitochondrial respiratory chain, all four subunits are encoded by nuclear DNA. The complementary DNAs of the flavoprotein and iron-sulfur protein subunit have been cloned and sequenced. ${ }^{10,11}$

We studied 2 sisters and 1 boy from 2 unrelated families with clinical symptoms and magnetic resonance imaging (MRI) signs of a progressive leukoencephalopathy. After the detection of accumulated succinate in cerebral and cerebellar white matter by proton magnetic resonance spectroscopy (MRS), a deficiency of complex II was demonstrated biochemically. Patient 1 was previously discussed in a review article. ${ }^{12}$
From the ${ }^{1}$ Department of Pediatrics and Neuropediatrics, Children's Hospital, University of Göttingen, Göttingen, Germany; ${ }^{2}$ Department of Pediatrics, Rikshospitalet, National Hospital University of Oslo, Oslo, Norway; ${ }^{3}$ Biomedizinische NMR Forschungs $\mathrm{GmbH}$ am Max-Planck-Institut für Biophysikalische Chemie, Göttingen, Germany; ${ }^{4}$ Nijmegen Center for Mitochondrial Disorders, Department of Pediatrics, University Medical Center, Nijmegen, the Netherlands; ${ }^{5}$ Children's Hospital Gilead, Bielefeld-Bethel, Germany; and ${ }^{6}$ Neuropathological Institute Gilead, Bielefeld-Bethel, Germany.
Received Dec 14, 2001, and in revised form Mar 4, 2002. Accepted for publication Mar 4, 2002.

Published online May 31, 2002, in Wiley InterScience (www.interscience.wiley.com). DOI: 10.1002/ana.10232

Address correspondence to Dr Brockmann, Department of Pediatrics and Neuropediatrics; Children's Hospital, Robert-Koch-Straße 40, 37075, Göttingen, Germany.

E-mail:kbrock@med.uni-goettingen.de 


\section{Patients and Methods}

Family History of Patients 1 and 2

A pedigree of this family is depicted in Figure 1. Patients 1 and 2 were the second and fifth children of consanguineous (first cousins), healthy parents of Turkish origin. Their oldest brother is healthy. Their mother's third gestation was a twin pregnancy. One twin died in utero, and the other twin boy was born prematurely at 26 weeks of gestation. He suffered from intraventricular hemorrhaging and now has spastic diplegia.

\section{Patient 1}

This girl was born at term without complications. Her birth weight of $2,470 \mathrm{~g}$ (3rd percentile) pointed to intrauterine growth retardation; her length and head circumference were normal. Although her length and head circumference increased within normal range, her weight remained below the 3rd percentile. Psychomotor development was normal until the age of 10 months. She sat at 7 months, crawled at 8 months, and pulled up to standing at 9 months. Parents first became worried by dysphoric behavior before-without preceding infection - a rapidly progressive loss of all motor skills was observed at 10 months. Within 3 weeks, she was unable to crawl or sit or hold her bottle. Her mental functions were preserved. On admission at 11 months, the child was extremely restless and irritable. There was marked spasticity and hyperreflexia in her legs and arms; Babinski's sign was present. Funduscopy was normal. Physical examination indicated no abnormalities apart from dystrophy (body weight, $1.7 \mathrm{~kg}$ below the $3 \mathrm{rd}$ percentile; height, 10 th percentile; head circumference, 75 th percentile). Electrocardiogram and echocardiography were normal.

After demonstration of an isolated complex II deficiency (discussed later), riboflavin, coenzyme $\mathrm{Q}$, and carnitine were supplemented. However, a progressive deterioration with in-

Fig 1. Pedigree of the family of Patients 1 and 2.

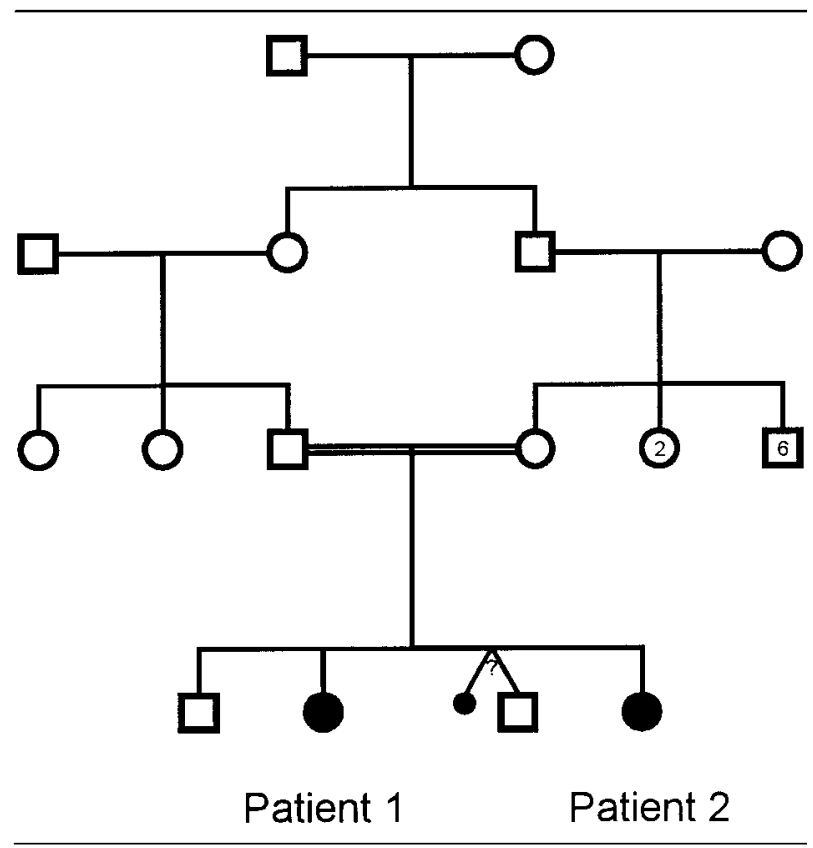

creasing spasticity and signs of brainstem dysfunction was observed. At the age of 18 months, the girl died as a result of multiorgan failure with severe lactic acidosis during a febrile infection.

\section{Patient 2}

This girl, the younger sister of Patient 1, was born after an uneventful pregnancy and delivery at term. Prenatal diagnosis for complex II deficiency was not sought by the parents. She was small for gestational age (birth weight, 1,740g), and her weight remained below the 3 rd percentile. Motor and mental development was normal during the first months: head control at 3 weeks, sitting at 7 months, and crawling at 8 months. She produced syllables and single words. As for her sister, dysphoric behavior caused early concern. Without any particular preceding event, a rapid motor deterioration occurred at the age of 10 months. She lost all motor skills within 4 weeks. On admission to our hospital, her body weight and length were below the 3rd percentile, and her head circumference was at the $3 \mathrm{rd}$ percentile. Social skills were adequate for age. Neurological examination showed a severe spastic paresis predominantly affecting her legs and dystonic posturing of her fingers. Funduscopy was normal. Electrocardiogram and echocardiography were normal.

\section{Patient 3}

This boy was the first of three children of unrelated Norwegian parents coming from neighboring areas. His siblings were healthy. The boy was delivered by caesarean section at 27 weeks of gestation as a result of his mother's preeclampsia. His birth weight was $820 \mathrm{~g}$, and his Apgar scores were 6, 8 , and 8 . He showed early visual contact and reactive smiling, crawled at 11 months, and walked unsupported at 16 months. He spoke his first words before 12 months of age. From the age of 20 months onward, increasing spasticity and clumsiness were observed, with a gradual loss of all major motor skills over a period of 16 months. He lost active speech but was able to understand others and appeared unaffected in his cognitive functions.

From then on, a slow improvement in most skills occurred spontaneously. He could sit up, learned to crawl again, and restarted to eat independently. He retained clinical signs of pyramidal tract lesion. His head circumference has followed the 25th percentile. At present (6 years of age), he is able to walk with support and to say a few words.

\section{Laboratory Investigations}

Biochemical studies including routine blood tests and assessments of amino acids and organic acids in urine, lysosomal enzymes, and very long-chain fatty acids were normal in $\mathrm{Pa}$ tients 1 and 3. No evidence was found for an infectious disorder. Plasma lactate (normal $<2.1 \mathrm{mmol} / \mathrm{L}$ ) was only occasionally elevated to $2.7,2.8$, and $2.4 \mathrm{mmol} / \mathrm{L}$ in Patients 1,2 , and 3 , respectively.

In cerebrospinal fluid, lactate was mildly increased to $2.3 \mathrm{mmol} / \mathrm{L}$ (normal $<2.1$ ) in Patient 1 and was normal in Patient 3. The total protein content was normal in Patient 1 and mildly elevated to $33 \mathrm{mg} / \mathrm{dL}$ (normal $<32$ ) in Patient 3. 


\section{Neuropathological Findings in Patient 1}

Brain weight was $1,190 \mathrm{~g}$ (normal: mean, 970g; SD, 160g). No abnormalities were noted on external inspection. On sectioning, all ventricles were compressed. There were several grayish, soft, sharply delineated lesions in central parts of the corpus callosum and the right internal capsule; in the walls of the third ventricle; in the medulla oblongata, cerebellar peduncles, and vermis; in the white matter of the cerebellar hemispheres; and in the upper cervical spinal cord. A large, symmetric, grayish softening of the centrum semiovale was observed.

Microscopic examination of white matter indicated loss of myelin, marked spongiform degeneration, astrocytosis, and intense vascular proliferation. Gray matter was affected to a lesser extent; neurons and axons were relatively preserved. Histopathological features and topic patterns of this multifocal spongiform encephalomyelopathy were consistent with Leigh syndrome.

\section{Magnetic Resonance Spectroscopy}

Written informed consent was obtained from the parents. Fully relaxed short-echo-time proton magnetic resonance (MR) spectra (TR/TE $=6,000 / 20 \mathrm{msec}, 64$ accumulations) were acquired with the use of a single-voxel stimulated echo acquisition mode localization sequence ${ }^{13}$ and the standard imaging head coil at 2.0T (Siemens Magnetom Vision, Erlangen, Germany). Volumes of interest were selected from T1weighted (3D FLASH) - and, in Patients 2 and 3, T2weighted (fast spin echo)—images, with sizes ranging from 4.1 to $12.5 \mathrm{ml}$. Spectral evaluation and quantification of absolute metabolite concentrations were accomplished as described elsewhere. ${ }^{12}$ Previous studies of regional age dependencies of cerebral metabolites ${ }^{14}$ provided age-matched controls. Major detectable metabolites include the neuroaxonal markers ${ }^{15}$ $\mathrm{N}$-acetylaspartate (NAA) and $\mathrm{N}$-acetylaspartylglutamate (tNAA), creatine and phosphocreatine $(\mathrm{tCr})$ as ubiquitous compounds linked to energy metabolism, choline-containing compounds involved in membrane turnover, the glial (astrocytic) marker ${ }^{16}$ myo-inositol, and lactate as an intermediate product of nonoxidative glucose consumption. In addition, high-resolution, one-dimensional and two-dimensional, $J$-resolved proton MRS studies of cerebrospinal fluid served to confirm the spectral assignment of the succinate proton resonance.

\section{Histopathological Studies (Skeletal Muscle)}

Biopsies from M. vastus lateralis were performed in Patients 1 and 3. Histochemical analyses were carried out according to routine protocols.

\section{Biochemical Investigations (Skeletal Muscle and Fibroblasts)}

The respiratory chain enzyme complex activities were measured according to the following methods: NADH:ubiquinone oxidoreductase, as described by Smeitink and colleagues; ${ }^{17}$ succinate:cyt c oxidoreductase; and $\mathrm{SDH}$ as described by Fischer and colleagues. ${ }^{18}$ Decylubiquinol: cyt c oxidoreductase was measured with decylubiquinol and horse cytochrome $\mathrm{c}$ as the electron donor and acceptor, respectively. Tween $20(0.04 \%)$ was added to break the mi- tochondria (H.A.C.M. Bentlage, unpublished data, 1996). Cytochrome c oxidase (Cox) was determined (with slight modifications) as described by Cooperstein and Lazarow, ${ }^{19}$ and citrate synthase was determined as described by Srere. ${ }^{20}$ For cultured fibroblasts, enzyme measurements were performed in mitochondria-enriched fractions; for muscle tissue, $600 \mathrm{~g}$ of a supernatant of a crude homogenate was used.

\section{Results}

\section{Magnetic Resonance Imaging}

PATIENTS 1 AND 2. In both Patients 1 and 2, MRI was first performed at 11 months of age. Although gray matter, basal ganglia, and ventricles were normal, both patients showed extensive T2-hyperintensities in central parts of supratentorial white matter with predominance in frontal and occipital lobes, as demonstrated in Figures 2A and B and Figure 3A, respectively. Demarcation to peripheral normal-appearing white matter was vague, and subcortical U-fibers were spared. Figure 3B depicts a distinct T1-hypointensity of cerebellar white matter bilaterally in Patient 2, which occurred earlier than in Patient 1 (not shown). In addition, follow-up investigations of Patient 1 at 13 and 17 months of age indicated further increases in white matter intensities in T2-weighted images.

PATIENT 3. MRI at the age of 24 months showed widespread T2-hyperintensities in cerebral periventricular white matter mainly involving frontal and occipital lobes. The corpus callosum and pons were also affected; subcortical U-fibers were spared. Gray matter and basal ganglia were normal. Follow-up MRI investigations at the ages of 32,39 , and 50 months showed gradual progression of these signal changes to more peripheral regions of supratentorial white matter and small cystic lesions in affected areas. T1- and T2weighted images of the last examination are shown in Figures $4 \mathrm{~A}$ and $\mathrm{B}$.

\section{Magnetic Resonance Spectroscopy}

PATIENT 1. As shown in Figures $2 \mathrm{C}$ to F, MR spectra from different brain regions of Patient 1 were obtained at the age of 13 months for left and right white matter (see Figs 2C and D, respectively), parieto-occipital gray matter (see Fig 2E), and basal ganglia (see Fig 2F). Quantitative analyses of absolute metabolite concentrations are summarized in Table 1 for the examinations at 13 and 17 months of age.

The most obvious result is the occurrence of a prominent resonance at a frequency of $2.40 \mathrm{ppm}$ in proton MR spectra of white matter, which is not present in the normal human brain. Because this signal was also observed in high-resolution proton MR spectra of cerebrospinal fluid obtained from this patient, twodimensional, J-resolved MRS techniques allowed its 


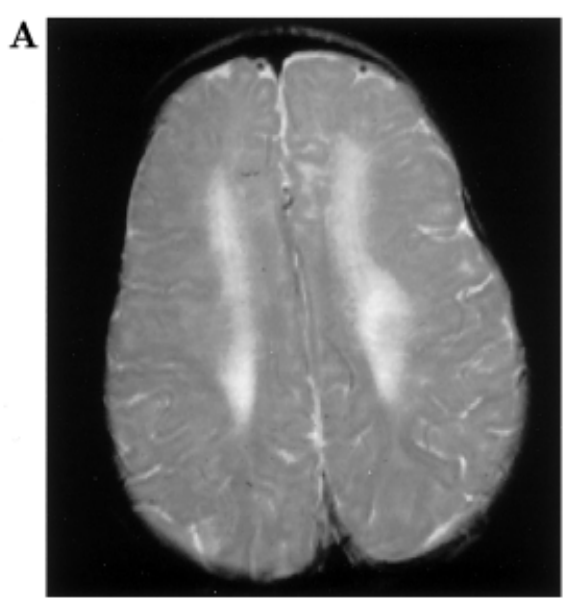

C

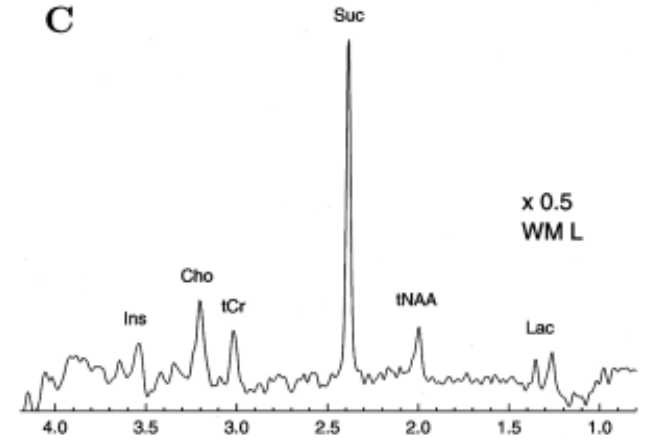

$\mathbf{E}$

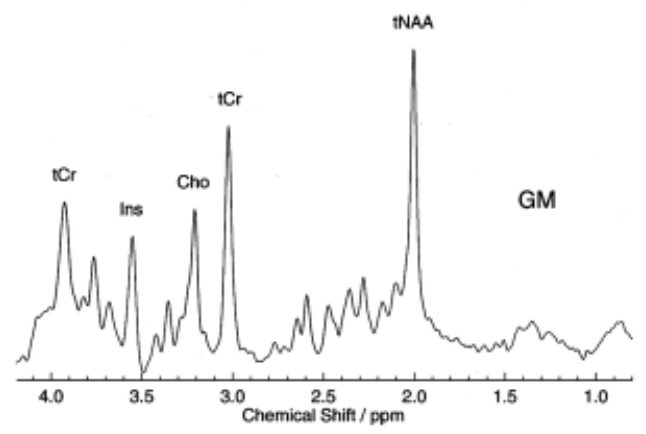

B

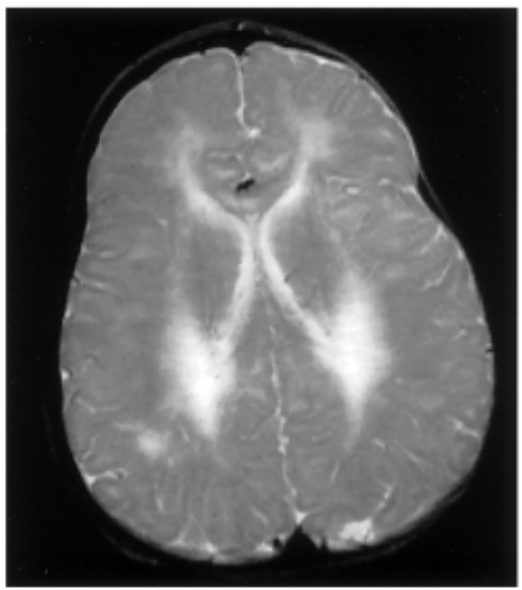

D

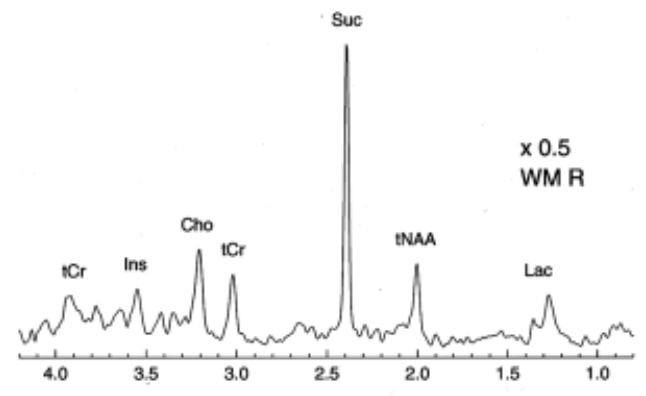

F

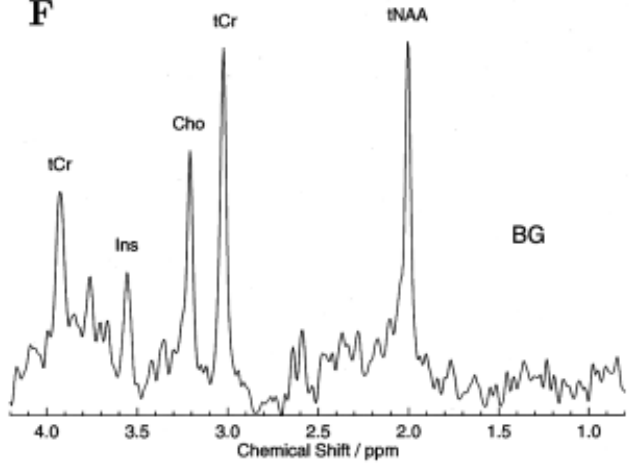

Fig 2. Patient 1. $(A, B)$ T2-weighted magnetic resonance $(M R)$ images at 11 months of age and $(C-F)$ localized proton $M R$ spectra (single-voxel stimulated echo acquisition mode, $T R / T E=6,000 / 20 \mathrm{~ms}, 64$ accumulations) at 13 months of age from (C, D) left-and right-hemispheric parieto-occipital white matter, (E) paramedian parietal gray matter, and (F) basal ganglia. Metabolites refer to $\mathrm{N}$-acetylaspartate and $\mathrm{N}$-acetylaspartylglutamate ( $t N A A)$, creatine and phosphocreatine ( $t C r$ ), choline-containing compounds (Cho), myo-inositol (Ins), lactate (Lac), and succinate (Suc). The spectral amplitudes of white matter (WM) are scaled down by a factor of 2 relative to those of gray matter $(G M)$ and basal ganglia (BG).

identification as a singlet proton resonance not coupled to other nuclear spins. Together with the chemical shift position, it may, therefore, be assigned to the four protons of the two equivalent methylene groups of succinate $\mathrm{HOOC}-\mathrm{CH}_{2}-\mathrm{CH}_{2}-\mathrm{COOH}$.

In addition, both spectra (see Figs 2C and D) and quantified metabolite concentrations (see Table 1) from cerebral white matter showed markedly reduced levels of tNAA and $\mathrm{tCr}$ as well as elevated lactate. The latter finding was even more pronounced at a follow-up MRS investigation at the age of 17 months. The observation of a mild but significant increase of myo-inositol at this stage agrees with the occurrence of astrocytosis.

In contrast to white matter, no succinate and lactate were detectable in cortical gray matter (see Fig 2E) and basal ganglia (see Fig 2F). With the two MRS examinations taken together, gray matter metabolite levels turned out to be rather unaffected apart from a mild reduction of tNAA. 


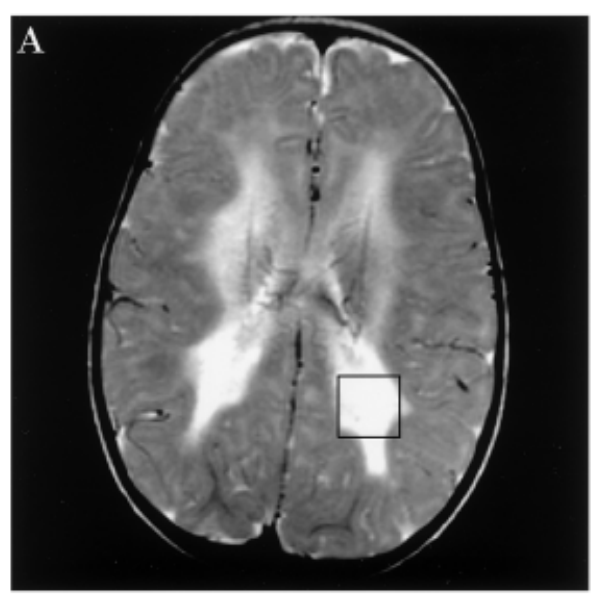

C

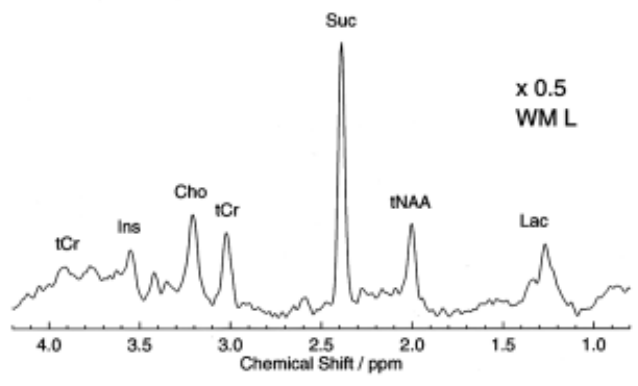

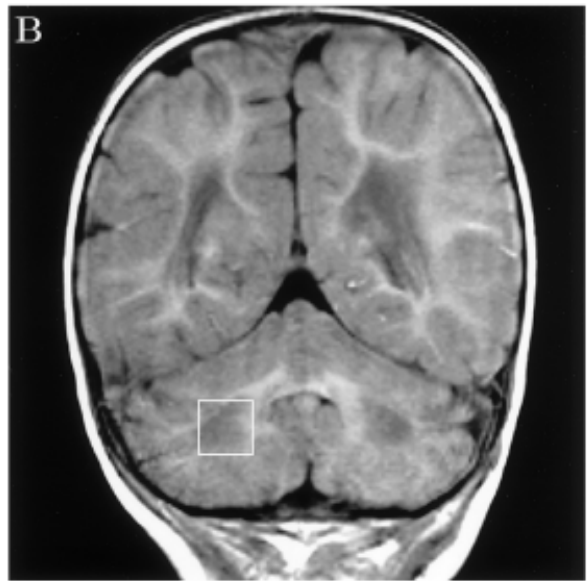

D

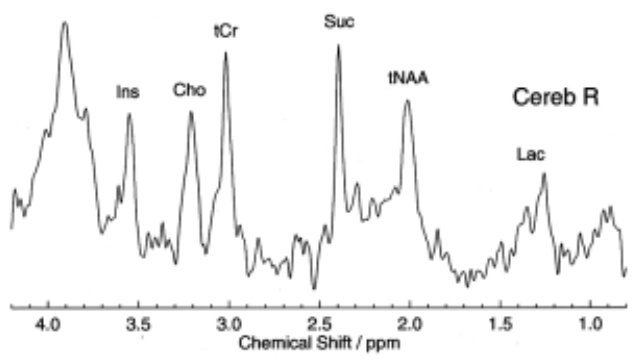

Fig 3. Patient 2 (sister of Patient 1). (A, B) T2- and T1-weighted magnetic resonance (MR) images and (C, D) localized proton MR spectra at 12 months of age from (C) left-hemispheric parieto-occipital white matter (WM; scaled down by a factor of 2) and (D) right-hemispheric cerebellum (Cereb). For other details, see Figure 2.

PATIENT 2. In general, proton MRS examinations of Patient 2 at 12 months of age showed the same pattern of metabolic abnormalities found in her sister (Patient 1). As demonstrated in Figure 3 and quantified in Table 2, both cerebral (see Fig 3C) and cerebellar white matter (see Fig 3D) showed decreased levels of tNAA and tCR as well as elevated lactate and prominent resonances from succinate. In this girl, gray matter was completely normal. In basal ganglia, there were no abnormalities apart from elevated tCR, as in her sister.

PATIENT 3. Proton MR spectra of cerebral white and gray matter of Patient 3 at 50 months of age are shown in Figures $4 \mathrm{C}$ and D. Table 3 summarizes corresponding metabolite concentrations and again confirms the presence of succinate and elevated lactate in cerebral white matter, although at slightly lower levels than in Patients 1 and 2. Furthermore, and in agreement with Patients 1 and 2, white matter showed decreased concentrations of tNAA and tCr. The significant enhancement of myoinositol suggests the presence of astrocytosis. The metabolite patterns of cortical gray matter and basal ganglia were normal except for a mild but significant decrease of $\mathrm{tCr}$ in basal ganglia.

\section{Skeletal Muscle Studies}

Muscle biopsy showed a weak SDH reaction with respect to normal controls in Patient 1. COX activity was normal. Reactions to $\mathrm{SDH}$ and $\mathrm{COX}$ were normal in Patient 3.

\section{Biochemical Analysis}

Biochemical analysis of skeletal muscle tissue (M. vastus lateralis) and cultured skin fibroblasts in Patient 1 and of fibroblasts in Patient 3 demonstrated severely decreased activities of SDH and succinate:cyt c oxidoreductase (Table 4). The activities of complexes I, III, and IV were normal in both children. As Patient 2 was examined only recently, an investigation of the activities of her respiratory chain enzymes are still underway.

\section{Discussion}

During this study of 3 children with a so far unclassified leukoencephalopathy, strongly elevated concentrations of succinate in cerebral and cerebellar white matter were detected with localized proton MRS. Biochemical investigations confirmed a deficiency of 


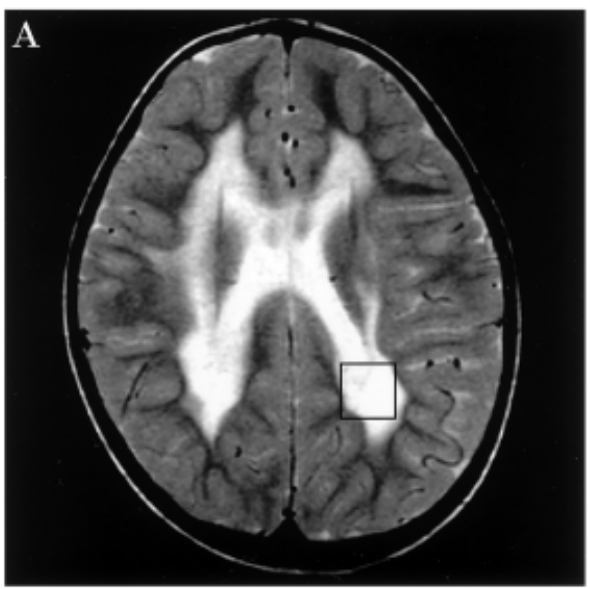

C

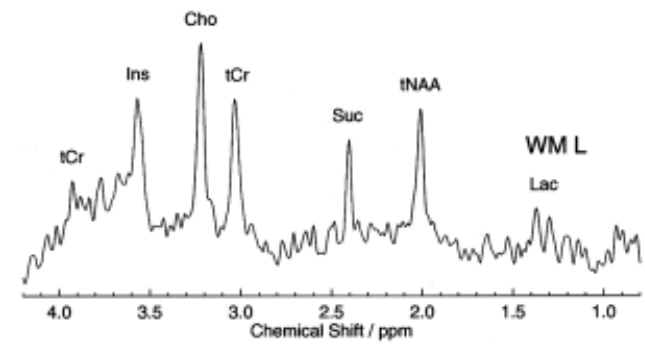

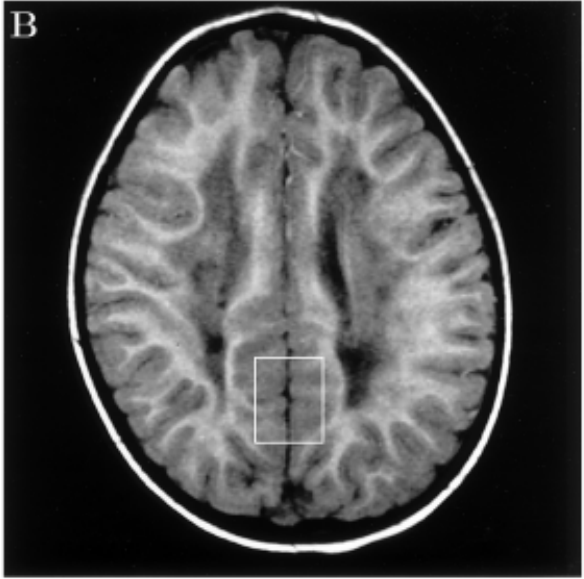

D

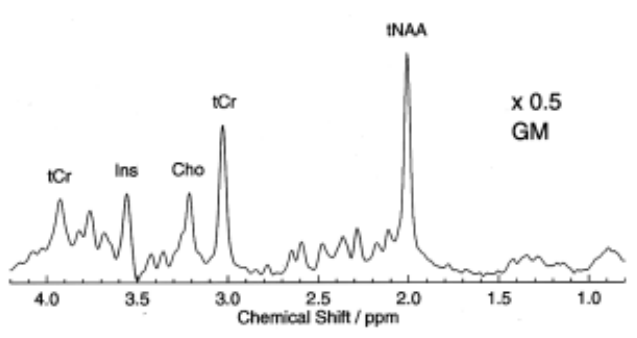

Fig 4. Patient 3 (unrelated to Patients 1 and 2). (A, B) T2- and T1-weighted magnetic resonance (MR) images and (C, D) localized proton MR spectra at 50 months of age from (C) left-hemispheric parieto-occipital white matter (WM) and paramedian parietal gray matter (GM; scaled down by a factor of 2). For other details, see Figure 2.

Table 1. Cerebral Metabolite Concentrations (mM) of Patient 1 at 13 and 17 Months of Age

tNAA tCr Cho Ins $\quad$ Lac Suc

White matter

13 months

RP

$1.9^{\mathrm{c}}$

$2.9^{\mathrm{c}}$

1.8

3.7

2.4

1.9

3.8

3.7

17 months

LP

$2.0^{\mathrm{c}}$

$1.9^{\mathrm{c}}$

RP

$2.9^{\mathrm{c}}$

$3.4^{\mathrm{c}}$

1.4

3.9

$4.9^{\mathrm{b}}$

6.9

4.7

Control $(\mathrm{n}=14)^{\mathrm{a}}$

$6.5 \pm 0.5$

$5.0 \pm 0.5$

$1.8 \pm 0.2$

$3.5 \pm 0.6$

7.1

Gray matter

13 months

PMP

17 months

PMP

Control $(\mathrm{n}=11)^{\mathrm{a}}$

$5.8^{\mathrm{b}}$

6.2

$7.5 \pm 0.7$

7.0

$6.9 \pm 0.7$

$8.7^{\mathrm{b}}$

$7.6 \pm 0.5$

6.5

$6.4 \pm 0.8$

1.5

1.2

$1.2 \pm 0.2$

2.2

$1.9 \pm 0.2$

$6.9 \pm 0.7$

13 months

Right
Control $(\mathrm{n}=8)^{\mathrm{a}}$

${ }^{a}$ Mean \pm standard deviation.

b $>2$ standard deviations from control.

c $>3$ standard deviations from control.

$\mathrm{LP}=$ left parietal; $\mathrm{RP}=$ right parietal; $\mathrm{PMP}=$ paramedian parietal. 
Table 2. Cerebral Metabolite Concentrations (mM) of Patient 2 at 12 Months of Age

\begin{tabular}{|c|c|c|c|c|c|c|}
\hline & tNAA & $\mathrm{tCr}$ & Cho & Ins & $\mathrm{Lac}$ & Suc \\
\hline \multicolumn{7}{|l|}{ White matter } \\
\hline & $3.9^{\mathrm{c}}$ & $3.5^{\mathrm{b}}$ & 1.6 & 3.2 & 4.8 & 8.3 \\
\hline Control $(\mathrm{n}=14)^{\mathrm{a}}$ & $6.5 \pm 0.5$ & $5.0 \pm 0.5$ & $1.8 \pm 0.2$ & $3.5 \pm 0.6$ & - & - \\
\hline \multicolumn{7}{|l|}{ Gray matter } \\
\hline PMP & 8.0 & 7.0 & 1.5 & 5.4 & - & - \\
\hline Control $(\mathrm{n}=11)^{\mathrm{a}}$ & $7.5 \pm 0.7$ & $6.4 \pm 0.8$ & $1.2 \pm 0.2$ & $4.4 \pm 0.9$ & - & - \\
\hline \multicolumn{7}{|l|}{ Basal ganglia } \\
\hline Left & 7.8 & $9.0^{\mathrm{b}}$ & 1.8 & 3.7 & - & - \\
\hline Control $(\mathrm{n}=8)^{\mathrm{a}}$ & $6.9 \pm 0.7$ & $7.6 \pm 0.5$ & $1.9 \pm 0.2$ & $3.7 \pm 0.5$ & - & - \\
\hline \multicolumn{7}{|l|}{ Cerebellum } \\
\hline Right & 5.1 & 6.7 & 1.8 & 5.2 & 4.6 & 3.7 \\
\hline Control $(\mathrm{n}=4)^{\mathrm{a}}$ & $5.7 \pm 0.5$ & $7.8 \pm 0.6$ & $1.9 \pm 0.3$ & $6.6 \pm 1.2$ & - & - \\
\hline
\end{tabular}

${ }^{\mathrm{a}}$ Mean \pm standard deviation.

b $>2$ standard deviations from control.

c>3 standard deviations from control.

$\mathrm{LP}=$ left parietal; $\mathrm{RP}=$ right parietal; $\mathrm{PMP}=$ paramedian parietal.

Table 3. Cerebral Metabolite Concentrations (mM) of Patient 3 at 50 Months of Age

\begin{tabular}{|c|c|c|c|c|c|c|}
\hline & tNAA & $\mathrm{tCr}$ & Cho & Ins & Lac & Suc \\
\hline \multicolumn{7}{|l|}{ White matter } \\
\hline LP & $2.9^{c}$ & $3.3^{\mathrm{c}}$ & 1.7 & $5.2^{\mathrm{b}}$ & 1.7 & 1.3 \\
\hline $\mathrm{RP}$ & $3.8^{\mathrm{c}}$ & $4.1^{\mathrm{b}}$ & 1.9 & $5.8^{c}$ & 1.5 & 0.5 \\
\hline Control $(\mathrm{n}=12)^{\mathrm{a}}$ & $7.2 \pm 0.7$ & $5.0 \pm 0.4$ & $1.9 \pm 0.2$ & $3.7 \pm 0.6$ & - & - \\
\hline \multicolumn{7}{|l|}{ Gray matter } \\
\hline PMP & 7.9 & 6.2 & 1.2 & 5.0 & - & - \\
\hline Control $(\mathrm{n}=16)^{\mathrm{a}}$ & $8.2 \pm 0.9$ & $6.4 \pm 0.7$ & $1.1 \pm 0.2$ & $4.7 \pm 0.4$ & - & - \\
\hline \multicolumn{7}{|l|}{ Basal ganglia } \\
\hline Right & 6.9 & $6.1^{\mathrm{b}}$ & 1.8 & 4.6 & - & - \\
\hline Control $(\mathrm{n}=13)^{\mathrm{a}}$ & $8.0 \pm 0.8$ & $7.9 \pm 0.6$ & $1.8 \pm 0.2$ & $3.8 \pm 0.9$ & & \\
\hline
\end{tabular}

${ }^{a}$ Mean \pm standard deviations.

b $>2$ standard deviations from control.

${ }^{c}>3$ standard deviations from control.

$\mathrm{LP}=$ left parietal; $\mathrm{RP}=$ right parietal; $\mathrm{PMP}=$ paramedian posterior

$\mathrm{SDH}$, the active part of complex II of the oxidative phosphorylation system, in 2 patients.

So far, the main findings of proton MRS studies of disorders of oxidative phosphorylation are characterized by the observation of elevated lactate with regional variation $^{21-23}$ and decreased tNAA as a sign of vital neuroaxonal tissue damage or loss. More specific metabolic abnormalities pointing to a particular metabolic disturbance as the cause of a mitochondrial encephalomyopathy have not been reported. For the first time, this work demonstrates the occurrence of strongly elevated succinate in white matter as a result of SDH deficiency.

Because of its low concentration under physiological conditions, succinate is not detectable by proton MRS of a healthy brain. ${ }^{14}$ It has been identified by in vivo MRS in brain abscesses as an intermediate product of bacterial metabolism, ${ }^{24,25}$ in certain cerebral infections, ${ }^{26,27}$ and in radiation-induced brain injuries. ${ }^{28}$

Complex II (succinate:ubiquinone oxidoreductase) deficiency accounts for approximately $2 \%$ of mitochondrial encephalomyopathies. ${ }^{29,30}$ Among a wide range of clinical presentations, leukodystrophy and Leigh syndrome have been reported to be associated with complex II deficiency. ${ }^{31,32}$

Although Patient 3 showed a milder clinical course and succinate and lactate concentrations in affected white matter not as high as the 2 sisters had (as measured by MRS), white matter changes as shown on MRI were more extensive than in the girls. The characteristic topological MRI pattern of Leigh syndrome with the involvement of basal ganglia and brainstem was not present in any of the patients. The MRSdetected metabolite levels of gray matter were mostly 


\begin{tabular}{|c|c|c|c|c|}
\hline & \multirow{2}{*}{$\frac{\text { Muscle }}{\text { Patient } 1}$} & \multicolumn{3}{|c|}{ Fibroblasts } \\
\hline & & Patient 1 & & Patient 3 \\
\hline $\begin{array}{l}\text { NADH:Q1 oxidoreductase } \\
\text { (CI) }\end{array}$ & 0.13 & 0.20 & & 0.20 \\
\hline Control range & $0.070-0.25^{\mathrm{a}}$ & & $0.11-0.26^{\mathrm{b}}$ & \\
\hline Succinate dehydrogenase (CII) & 0.043 & 0.03 & & 0.02 \\
\hline Control range & $0.067-0.177^{\mathrm{a}}$ & & $0.07-0.18^{\mathrm{b}}$ & \\
\hline $\begin{array}{l}\text { Decylubiquinol: cytochrome c } \\
\text { oxidoreductase (CIII) }\end{array}$ & 2.73 & 1.82 & & 1.87 \\
\hline Control range & $2.2-6.6^{\mathrm{a}}$ & & $1.27-2.62^{\mathrm{b}}$ & \\
\hline $\begin{array}{l}\text { Succinate: cytochrome c oxi- } \\
\text { doreductase (CII+CIII) }\end{array}$ & 0.11 & 0.075 & & 0.05 \\
\hline Control range & $0.30-0.97^{\mathrm{a}}$ & & $0.16-0.44^{\mathrm{b}}$ & \\
\hline Cytochrome c oxidase (CIV) & 0.90 & 0.81 & & 0.82 \\
\hline Control range & $0.81-3.12^{\mathrm{a}}$ & & $0.68-1.19^{\mathrm{a}}$ & \\
\hline Citrate synthase (CS) & 40 & 187 & & 214 \\
\hline Control range & $37-162^{c}$ & & $144-257^{\mathrm{d}}$ & \\
\hline
\end{tabular}

${ }^{a}$ in $\mathrm{mU}$ per $\mathrm{mU}$ citrate sythase (mitochondria-enriched fraction).

$\mathrm{b}_{\text {in }} \mathrm{mU}$ per $\mathrm{mU}$ cytochrome $\mathrm{c}$ oxidase.

$c_{\text {in }} \mathrm{mU}$ per $\mathrm{mg}$ protein.

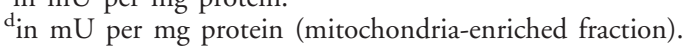

within normal ranges, including lactate in basal ganglia.

The different clinical courses observed in our patients cannot be explained by the biochemical findings presented. The residual activity of complex II measured in fibroblasts of Patients 1 and 3 is similarly low. No information about the residual activity in other tissues, such as the brain, is available. A presumed difference in protein subunit defects might influence the phenotype, but these investigations are not yet completed. Profound deficiencies in complex II activity resulting from mutations in the flavoprotein gene of SDH are reported to present as Leigh syndrome with characteristic basal ganglia pathology. ${ }^{33}$

To our knowledge, this is the first report of highly elevated concentrations of succinate in proton MR spectra of the brain in disorders of the oxidative phosphorylation system. These observations of a characteristic metabolic abnormality for complex II deficiencies illustrate the unique potential of proton MRS as a noninvasive tool for studying disorders of brain metabolism. Taken together, there are now at least four neurometabolic disorders with specific MRS findings: Canavan's disease (elevated tNAA), ${ }^{34}$ NAA deficiency (lack of tNAA), ${ }^{35}$ disorders of creatine metabolism (lack of $\mathrm{tCr}$ ), ${ }^{36}$ and SDH deficiency as identified here.

\section{References}

1. Smeitink J, van den Heuvel L, DiMauro S. The genetics and pathology of oxidative phosphorylation. Nat Rev Genet 2001; 2:342-352.

2. Brown GK, Squier MV. Neuropathology and pathogenesis of mitochondrial diseases. J Inherited Metab Dis 1996;19: 553-572.
3. Bourgeron T, Rustin P, Chretien D, et al. Mutation of a nuclear succinate dehydrogenase gene results in mitochondrial respiratory chain deficiency. Nat Genet 1995;11:144-149.

4. Rahman S, Brown RM, Chong WK, et al. A SURF1 gene mutation presenting as isolated leukodystrophy. Ann Neurol 2001; 49:797-800.

5. Taylor RW, Birch-Machin MA, Schaefer J, et al. Deficiency of complex II of the mitochondrial respiratory chain in late-onset optic atrophy and ataxia. Ann Neurol 1996;39:224-232.

6. Reichmann H, Angelini C. Single muscle fibre analyses in 2 brothers with succinate dehydrogenase deficiency. Eur Neurol 1994;34:95-98.

7. Sugimoto J, Shimohira M, Osawa Y, et al. A patient with mitochondrial myopathy associated with isolated succinate dehydrogenase deficiency. Brain Dev 2000;22:158-162.

8. Rustin P, Lebidois J, Chretien D, et al. The investigation of respiratory chain disorders in heart using endomyocardial biopsies. J Inherited Metab Dis 1993;16:541-544.

9. Ackrell BAC, Johnson MK, Gunsalus RP, Cecchini G. Structure and function of succinate dehydrogenase and fumarate reductase. In: Muller F, ed. Biochemistry of flavoenzymes. Boca Raton, FL: CRC, 1992:229-297.

10. Morris AA, Farnsworth L, Ackrell BA, et al. The cDNA sequence of the flavoprotein subunit of human heart succinate dehydrogenase. Biochim Biophys Acta 1994;1185:125-128.

11. Kita K, Oya H, Gennis RB, et al. Human complex II (succinate-ubiquinone oxidoreductase): cDNA cloning of iron sulfur (Ip) subunit of liver mitochondria. Biochem Biophys Res Commun 1990;166:101-108.

12. Frahm J, Hanefeld F. Localized proton magnetic resonance spectroscopy of brain disorders in childhood. In: Bachelard HS, ed. Magnetic resonance spectroscopy and imaging in neurochemistry. New York: Plenum, 1997:329-402.

13. Frahm J, Michaelis $T$, Merboldt $\mathrm{KD}$, et al. Improvements in localized ${ }^{1} \mathrm{H}-\mathrm{NMR}$ spectroscopy of human brain. Water suppression, short echo times, and $1 \mathrm{~mL}$ resolution. J Magn Reson 1990;90:464-473. 
14. Pouwels PJ, Brockmann K, Kruse B, et al. Regional age dependence of human brain metabolites from infancy to adulthood as detected by quantitative localized proton MRS. Pediatr Res 1999;46:474-485.

15. Birken DL, Oldendorf WH. N-acetyl-L-aspartic acid: a literature review of a compound prominent in ${ }^{1} \mathrm{H}$ NMR spectroscopic studies of the brain. Neurosci Biobehav Rev 1989;13: 23-31.

16. Brand A, Richter-Landsberg C, Leibfritz D. Multinuclear NMR studies on the energy metabolism of glial and neuronal cells. Dev Neurosci 1993;15:289-298.

17. Smeitink J, Sengers R, Trijbels F, van den Heuvel L. Human NADH:ubiquinone oxidoreductase. J Bioenerg Biomembr 2001;33:259-266.

18. Fischer JC, Ruitenbeek W, Berden JA, et al. Differential investigation of the capacity of succinate oxidation in human skeletal muscle. Clin Chim Acta 1985;153:23-36.

19. Cooperstein SJ, Lazarow A. A microspectrophotometric method for the determination of cytochrome $\mathrm{c}$ oxidase. J Biol Chem 1951;189:665-670.

20. Srere PA. Citrate synthase, EC 4.1.3.7. citrate oxaloacetate-lyase (CoA-acetlylating). Methods Enzymol 1969;13:3-11.

21. Detre JA, Wang ZY, Bogdan AR, et al. Regional variation in brain lactate in Leigh syndrome by localized ${ }^{1} \mathrm{H}$ magnetic resonance spectroscopy. Ann Neurol 1991;29:218-221.

22. Kraegeloh-Mann I, Grodd W, Schoning M, et al. Proton spectroscopy in five patients with Leigh's disease and mitochondrial enzyme deficiency. Dev Med Child Neurol 1993;35:769-776.

23. Gadian DG, Leonard JV. The role of magnetic resonance spectroscopy in the investigation of lactic acidosis and inborn errors of energy metabolism. J Inherited Metab Dis 1996;19: $548-552$.

24. Demaerel P, Van Hecke P, Van Oostende S, et al. Bacterial metabolism shown by magnetic resonance spectroscopy. Lancet 1994;344:1234-1235.

25. Remy C, Grand S, Lai ES, et al. ${ }^{1} \mathrm{H}$ MRS of human brain abscesses in vivo and in vitro. Magn Reson Med 1995;34: $508-514$.
26. Siegal JA, Cacayorinb ED, Nassif AS, et al. Cerebral mucormycosis: proton MR spectroscopy and MR imaging. Magn Reson Imaging 2000;18:915-920.

27. Pandit S, Lin A, Gahbauer H, et al. MR spectroscopy in neurocysticercosis. J Comput Assist Tomogr 2001;25:950-952.

28. Yeung DK, Chan Y, Leung $S$, et al. Detection of an intense resonance at $2.4 \mathrm{ppm}$ in ${ }^{1} \mathrm{H}$ MR spectra of patients with severe late-delayed, radiation-induced brain injuries. Magn Reson Med 2001;45:994-1000.

29. Rustin P, Bourgeron T, Parfait B, et al. Inborn errors of the Krebs cycle: a group of unusual mitochondrial diseases in human. Biochim Biophys Acta 1997;1361:185-197.

30. Van den Heuvel L, Smeitink J. The oxidative phosphorylation (OXPHOS) system: nuclear genes and human genetic diseases. Bioessays 2001;23:518-525.

31. Bourgeois M, Goutieres F, Chretien D, et al. Deficiency in complex II of the respiratory chain presenting as a leukodystrophy in two sisters with Leigh syndrome. Brain Dev 1992;14: 404-408.

32. Pinard JM, Marsac C, Barkaoui E, et al. Syndrome de Leigh et leukodystrophie par déficit partiel en succinate déshydrogénase: régression sous riboflavine. Arch Pediatr 1999;6:421-426.

33. Parfait B, Chretien D, Rotig A, et al. Compound heterozygous mutations in the flavoprotein gene of the respiratory chain complex II in a patient with Leigh syndrome. Hum Genet 2000;106:236-243.

34. Grodd W, Krageloh-Mann I, Petersen D, et al. In vivo assessment of $\mathrm{N}$-acetylaspartate in brain in spongy degeneration (Canavan's disease) by proton spectroscopy. Lancet 1990;336: 437-438.

35. Martin E, Capone A, Schneider J, et al. Absence of $\mathrm{N}$-acetylaspartate in the human brain: impact on neurospectroscopy? Ann Neurol 2001;49:518-521.

36. Stöckler S, Holzbach U, Hanefeld F, et al. Creatine deficiency in the brain: a new, treatable inborn error of metabolism. Pediatr Res 1994;36:409-413. 